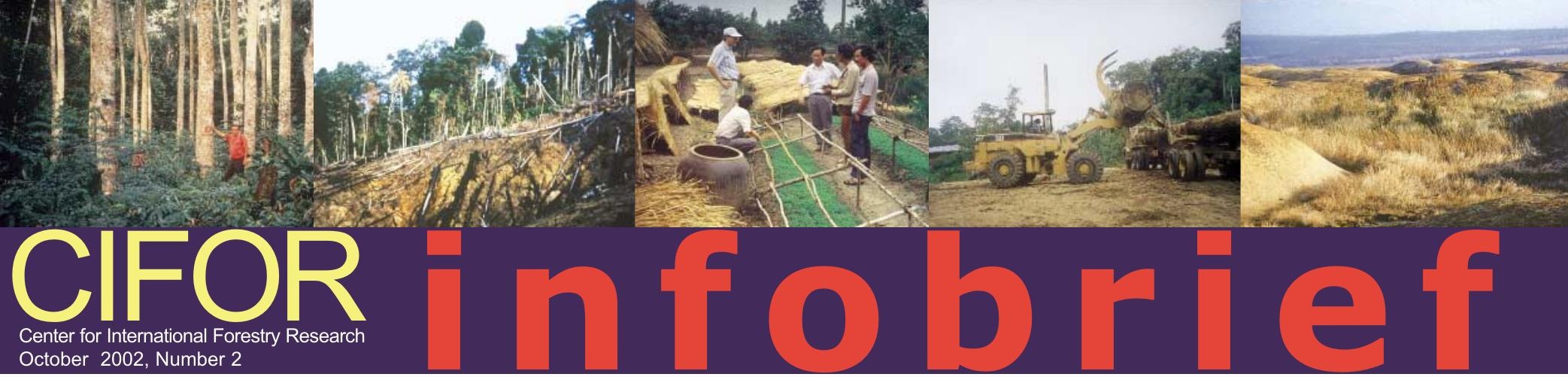

\title{
Making forest carbon markets work for low-income producers
}

\section{Key points}

- Many types of forest carbon projects can meet livelihood needs.

- Community-friendly projects can meet carbon offset criteria. Community-friendly carbon projects can be cost-effective for investors.

- Clean Development Mechanism (CDM) rules should encourage the participation of community forest and agroforestry producers, and protect them against major livelihood risks.

- National governments can play a pivotal role in promoting livelihood-enhancing projects.

- Innovations from pilot initiatives can be used to design profitable projects.

Forest carbon projects could potentially enhance the incomes and environment of hundreds of thousands, if not millions, of some of the world's poorest people, while providing real, climate-significant carbon offsets. But this opportunity will only be realized by adopting suitable rules for the CDM, applying innovations by business and social entrepreneurs to lower transaction costs, and taking public action to reduce risks to both investors and communities.

\section{The potential of forest carbon projects to reduce poverty}

In 1992, the United Nations Conference on Environment and Development established the Framework Convention on Climate Change (UNFCCC) to stabilize greenhouse gases at a level that would prevent dangerous changes to the climate. In December 1997, 39 industrialised nations agreed at a UNFCCC meeting to limit emissions of greenhouse gases, the most important of which is carbon dioxide. This became known as the Kyoto Protocol which specified legally binding commitments by most industrialized countries to reduce their collective greenhouse gas emissions by at least 5 percent compared to 1990 levels by the period 20082012. With the commitments announced at the World Summit for Sustainable Development in Johannesburg, the Protocol is expected to be ratified soon.

The CDM of the Kyoto Protocol allows industrialized countries to meet part of their obligation by financing energy and land use projects in developing countries. Agreement on the core elements of the CDM was reached in 2001, including the decision to allow industrialized countries to meet part of their emissionreduction commitments (up to a maximum of one percent of their 1990 emissions, for each year of the commitment period) by carrying out specified afforestation and reforestation projects in developing countries.

Many thoughtful observers are concerned about what sort of forestry projects will be funded by the CDM. For example, promoting large-scale industrial plantations or massive reforestation schemes with exotic tree species could threaten local livelihoods, land rights and ecosystems. There are many other types of project that could benefit local livelihoods and still reduce emissions. But the CDM itself, national policymakers and project organizers will have to take proactive measures to make forest carbon markets work for local producers.

\section{Forest carbon projects can meet livelihood needs}

Carbon projects that promote agroforestry, small-scale plantations, natural forest regeneration, forest gardens (agroforests) and improved forest fallows will improve the livelihoods of small-scale farmers, communities and indigenous peoples. Such projects give local people greater influence over local land-management decisions and strengthen local businesses and social organization. Because farmers and communities usually plant trees in small patches or seek to restore depleted native vegetation in the landscape, these projects can have positive environmental benefits, including conservation of locally important biodiversity, improved water quality and supply, and control of soil erosion and sedimentation (Table 1).

Livelihood risks. In contrast with large-scale plantations, livelihood risks from these types of projects are minimal, so long as tree species and configuration are compatible with other farm and food needs, and if community forest projects equitably distribute costs and benefits.

Investor and buyer risks. Community-friendly carbon projects reduce the risk of plantation failure, damage and loss to fire, and the cost of resolving conflicts with local communities. Projects with obvious local benefits enhance a company's reputation.

Community-friendly projects can meet carbon offset criteria. Community-friendly projects can be designed to meet CDM criteria for carbon benefits, additionality, leakage and duration. 
Table 1. Types of forest carbon projects with high local livelihood benefits

$\begin{array}{ll}\text { Forest project type } & \begin{array}{l}\text { Approach } \\ \text { Increase tree-growing and forest cover on farms (windbreaks, } \\ \text { filter strips, fodder banks, border strips) } \\ \text { Small plantations of fast-growing trees, in deforested or } \\ \text { Small-scale pulp or timber plantations }\end{array} \\ \begin{array}{l}\text { degraded areas on farms or community lands } \\ \text { Convert land under annual crops or pasture to multi-strata } \\ \text { Forest gardens (agroforests) }\end{array} & \begin{array}{l}\text { Convert land under annual crops or pasture to secondary forest } \\ \text { fallows that produce non-timber forest products }\end{array} \\ \text { Secondary forest fallows } & \begin{array}{l}\text { Rehabilitate or regenerate degraded natural forests on farms } \\ \text { or community lands; develop sustainable forest management } \\ \text { Forest rehabilitation and regeneration }\end{array} \\ & \text { system with local communities }\end{array}$

Carbon benefits. Logged forest, agroforests, tree crops, timber plantations and secondary forest fallows store less carbon than rainforest, but still much more than annual crops and pastures (Figure 1). Any intervention that encourages conversion from a lower to a higher carbon-storing land use will contribute to net carbon storage. For example, assisting regeneration of dry secondary forests in central India could double carbon sequestration from 27.3 to $55.2 \mathrm{t} / \mathrm{ha}$ in 10 years, at very modest cost. The carbon benefits of agroforestry are lower than high forest, but suitable cropland is extensive in the tropics. About 126 million hectares could be converted globally to agroforestry, sequestering $390 \mathrm{MtC}$ per year, in ways that also increase farm productivity and income.

Project duration. Carbon is stored only while the forest or its harvested products exist. Several methods have been developed to take into account the variable duration of most agroforestry and forestry production systems, and the 'true' value of forest carbon for climate impact. These include the tonne-year method of carbon accounting, temporary credits and large-area project design.

Leakage. Under the CDM, if project activities result in an increase in emissions outside project boundaries, these new emissions will be deducted from the credits earned. This is known as leakage. Most livelihoodenhancing types of forest carbon projects should have little leakage, unless situated on the forest frontier or if conversion of land from cropland to forest cover displaces crop production to other forested areas. Projects that increase forest resources in forest-scarce areas may provide 'negative' leakage, by increasing local food supply and wood products.

Additionality. CDM projects must demonstrate that the reductions achieved by the project would not have occurred without the project. Thus, forest carbon projects must show that barriers exist to the adoption of land uses that increase carbon sequestration. This should not be difficult to establish in areas where institutional barriers (like lack of planting material or technical assistance) prevent profitable forestry and agroforestry systems from developing.

Community-friendly carbon projects can be costeffective for investors. The potential for livelihoodenhancing forest carbon projects to compete for buyers (with large-scale forest plantations, CDM energy projects and other options) will depend on their costeffectiveness in producing certifiable carbon offsets.

Production costs. Estimates from Brazil, China, India and Thailand indicate that the cost of carbon emission offsets from large-scale industrial plantations could, in many cases, be under $\$ 5 / \mathrm{tC}$, if carried out in lands with low opportunity cost. Producing offsets through forest rehabilitation and conversion to agroforests range from $\$ 3$ to $\$ 20 / \mathrm{tC}$. Production costs of various kinds of agroforestry, small-scale farm and community plantations may be in the range of $\$ 8-30 / \mathrm{tC}$. Costs are higher for projects that seek to convert highvalued cropland to forest cover. Thus, suitably targeted forest projects can produce carbon offsets at the predicted market price of $\$ 15-20 / \mathrm{tC}$.

Transaction costs. These include the cost of providing information about carbon benefits to potential buyers, obtaining information about project partners, organizing project participants, capacity building and ensuring parties fulfill their obligations. Transaction costs per unit of emission reduction are likely to be

Figure 1. Above-ground time-averaged and total soil carbon $(0-20 \mathrm{~cm})$ for ASB benchmark sites in Brazil, Cameroon and Indonesia

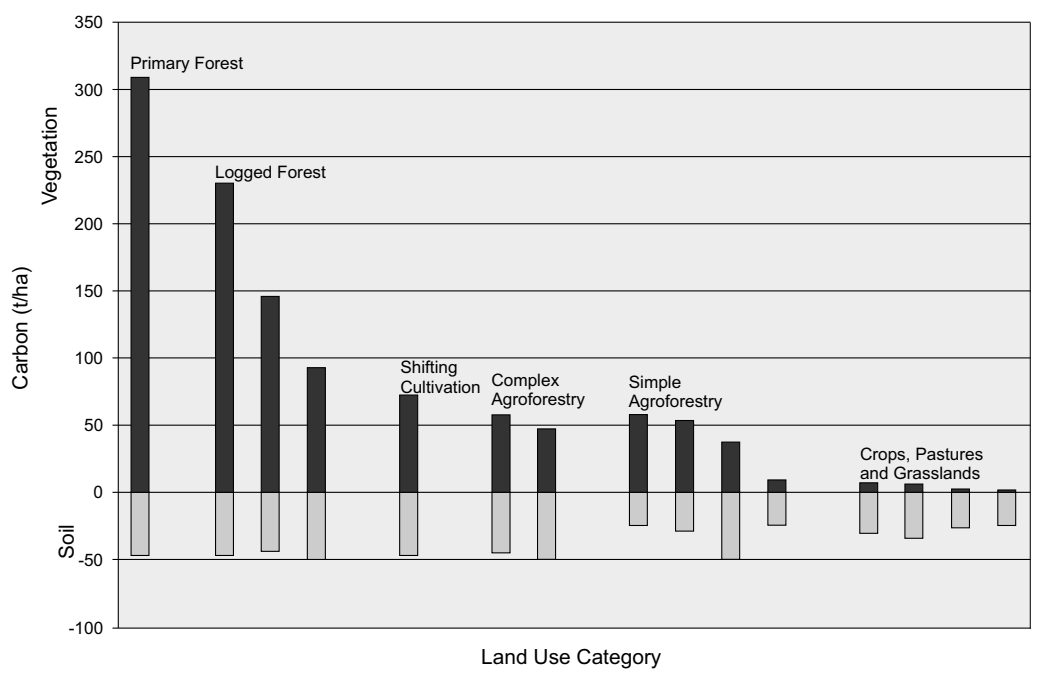

Source: Tomich et al. 2002 
higher for projects involving many smallholders and forest communities. Projects with smaller land areas may lack economies of scale. While improved efficiencies have greatly reduced transaction costs of some pilot community carbon projects, they remain a challenge to project development.

\section{Making forest carbon markets work for local producers}

Proactive efforts are needed to enable CDM forestry projects with local benefits to compete effectively in carbon trading markets.

\section{Recommendations for the Clean Development Mechanism}

CDM rules should encourage the participation of community forest and agroforestry producers, and protect them against major livelihood risks, while still meeting investor needs and rigorously ensured carbon offset goals.

\section{Recommendations for the Clean Development} Mechanism

1. Require social impact assessments for CDM projects.

2. Establish minimum standards for stakeholder consultations.

3. Harmonize the CDM with social principles of other global conventions.

4. Broaden the definition of afforestation and reforestation.

5. Promote measures to reduce transaction costs.

6. Establish international capacity building and advisory services.

Require social impact assessments for CDM projects. Social impact assessments (SIA) should be required for all CDM projects, at both the project proposal and certification stages. Publication of the results would promote transparency, and could be used by all stakeholders, including local communities and investors seeking socially responsible projects. Some minimum uniform criteria should be recognized.

Impose minimum standards for stakeholder consultation. Adequate stakeholder consultation could go a long way towards addressing the social risks of projects. Stakeholder consultations are mandatory under the Marrakesh Accords of November 2001, so minimum standards should be required for implementing them.

Harmonize the CDM with social principles of other global conventions. The Kyoto Protocol requires that activities to meet emission reduction commitments take into account commitments under relevant international environmental agreements. Minimum standards for project certification could be established in line with the Convention for
Conservation of Biodiversity and the Convention to Combat Desertification, in relation to local protections, indigenous rights, compensation for loss of rights and involvement in major management decisions.

Include diverse land uses in the definition of afforestation and reforestation. Agroforestry, assisted natural regeneration, forest rehabilitation, forest gardens and improved forest fallow projects should all be eligible for CDM, as they offer a low-cost approach to carbon sequestration, while offering fewer social risks and significant community and biodiversity benefits. Short-duration tree-growing activities should be permitted, with suitable discounting. Limiting the range of project types would introduce forest product market distortions unfairly favoring large plantations.

Promote measures to reduce transaction costs. According to the Marrakesh Accords, small-scale projects (i.e. those whose annual emission offsets are less than 15,000 t CO2) will benefit from simplified ways for determining baselines and monitoring carbon emissions. Agroforestry and community forestry projects should be specified as eligible for simplified modalities. Also, simplified emission reduction credits can be calculated using standardized reference emission rates for different emission reduction/storage activities in specific locations, determined and verified by independent bodies; an uncertainty discount could be applied. These could significantly reduce costs of community-based projects.

Establish international capacity building and advisory services. The successful promotion of livelihoodenhancing CDM forestry projects will require investment in capacity-building and advisory services for potential investors, project designers and managers, national policymakers and leaders of local organizations and federations. Workshops could explicitly address design and implementation of projects to enhance local livelihoods. Regional centers could be established to assist countries and communities involved in forest carbon trading, such as that developed by the International Fund for Agricultural Development in Asia.

\section{Stimulating community carbon investment} The principal actors in the CDM are the buyers and sellers of carbon emission credits. However, national governments will play a pivotal role in promoting livelihood-enhancing forest carbon projects. They can provide clear rules and procedures to encourage carbon investment in suitable areas where conditions are promising. Governments can protect local people by establishing clear criteria for social impact assessments, securing forest and land rights in potential project areas and establishing clear rights to forest carbon. Governments can catalyse the development of business support services for community carbon credit producers, and simplify forest market regulations to enhance income potential. Such actions would make forest carbon projects more attractive to private investors because they would reduce risks to their reputation and 
improve the likelihood of achieving targeted carbon offsets at the agreed price.

\section{Recommendations for the Clean Development}

Mechanism

1. Plan CDM projects within a national development framework.

2. Establish national criteria for social impact assessments.

3. Secure forest access and ownership rights for local people.

4. Establish forest carbon rights for local people.

5. Promote business support services for local forest producers.

6. Reform forest market and regulatory policy.

\section{Designing projects to reduce cost and risk} Innovations emerging from pilot carbon trading and other forestry initiatives can be used to design more cost-effective, livelihood-enhancing forest carbon projects. Participatory forest project planning and implementation can be more successful and less expensive than large centrally managed projects. Methods for participatory forestry planning are well developed and adaptable to forest carbon projects, as are methods to improve transparency in investorcommunity agreements and partnerships.

Suitable mechanisms for compensating local producers for carbon offsets could include:

- payments to farmers for trees established;

- payments to communities for forest establishment or protection;

- investments in extension, tree nurseries, marketing, and other services to enable local adoption of forestry or agroforestry systems not otherwise possible; and

- rewarding communities with improved public services or rights to resources.

The prospect of carbon emissions trading has stimulated institutional innovations to reduce project marketing costs and investor risks. These include 'bundling' together local projects to market to investors as a single large project (such as FUNDECOR in Costa
Rica); pooling investments of different types and locations to spread risks (such as the Face Foundation carbon projects); and branding of socially responsible investments to sell to interested buyers. New mechanisms to make insurance accessible to livelihoodenhancing forest carbon projects are needed, such as partial risk guarantees by multilateral financial institutions, so that a higher share of payments can be made to producers for early establishment costs.

Institutional innovations can provide economies of scale and specialization. Companies or agencies can provide specialised business services for low-income producers (for example, in negotiating deals or design of monitoring systems). Locally accountable intermediary organisations can manage projects and mediate between investors and local people (such as a local environmental group in the Scolel-Té project in Mexico). In area-based 'bubble projects' an entire jurisdiction (e.g., a municipality), rather than individual farmers or communities, commits to a defined increase in forest cover. This reduces leakage, increases land-use flexibility and reduces monitoring costs.

Transaction costs can be reduced by developing carbon projects in communities with active local organisations and participatory development programmes in place, with community representatives already selected and authorised to negotiate with outsiders and diagnoses of local needs and priorities already completed. For example, a proposed carbon project in Harda, India, relies on existing hamlet and federation institutions established for community forestry.

Recommendations for developers of forest carbon projects

1. Maximize project success through strong community participation.

2. Select the most suitable compensation mechanisms.

3. Enhance the profitability of new land uses.

4. Increase transparency in investor-community partnerships.

5. Reduce project marketing costs and investor risks.

6 . Increase scale and reduce costs of communitybased CDM projects.
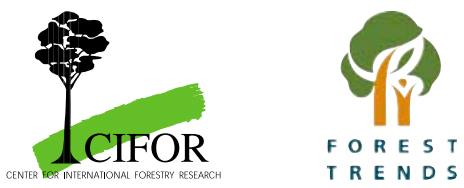
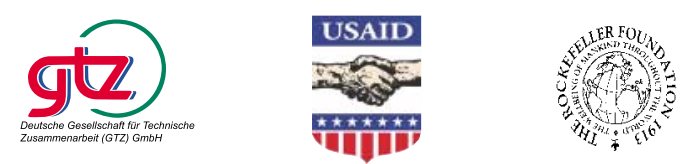

This infobrief was compiled by Joyotee Smith, formerly an economist at CIFOR, Bogor, Indonesia (e.smith@cgiar.org) and Sara J. Scherr, senior policy analyst at Forest Trends, Washington, DC, USA (Sscherr@forest-trends.org). The text is based on a longer policy report, Forest Carbon and Local Livelihoods: Assessment and Policy Recommendations, co-published by CIFOR and Forest Trends, Bogor, Indonesia. The paper can be downloaded from www.cifor.cgiar.org or www.forest-trends.org
Center for International Forestry Research

office: Jalan CIFOR, Situ Gede, Sindang Barang, Bogor Barat 16680, Indonesia

mailing: P.O. Box. 6596 JKPWB, Jakarta 10065, Indonesia

Tel: +62(251) 622622 Fax: +62(251) 622100

E-mail: cifor@cgiar.org Website: www.cifor.cgiar.org

Cover photos: Carol J.P. Colfer, Christian Cossalter, Haris Iskandar

Sandra Mbanefo (WWF) and Hari Priyadi

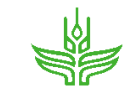

